\title{
A CRÍTICA DE PONTA-CABEÇA: SOBRE A SIGNIFICAÇÃO DE KANT NO PENSAMENTO DE FOUCAULT
}

Alexandre ALVES ${ }^{1}$

- RESUMO: Este artigo pretende avaliar a relação que Foucault estabelece com a modernidade, tendo como fio condutor seu vínculo com o pensamento de Kant. Aborda-se, num primeiro momento, a leitura que Foucault faz de Kant na época em que estava escrevendo As Palavras e as Coisas, observando uma tensão entre o projeto crítico e o antropologismo kantiano e, num segundo momento, interroga-se sua relação com Kant a partir de alguns de seus últimos textos, nos quais Foucault procura uma "ontologia do presente".

- PALAVRAS-CHAVE: Aufklärung; crítica; modernidade; arqueologia; genealogia; kantismo.

\section{Introdução}

Em 1984, um certo Maurice Florence assinou o verbete "Michel Foucault" para o Dictionnaire des Philosophes, editado pela PUF sob a direção do filósofo Denis Huisman. Neste verbete, para espanto daqueles que consideravam Foucault um autor na linha de frente do pós-modernismo, o pensamento de Foucault é inscrito na descendência da filosofia crítica kantiana:

Se Foucault se inscreve na tradição filosófica, é na tradição crítica, que é a de Kant, e se poderia chamar seu empreendimento História crítica do pensamento. Por esta última não se deveria entender uma história das idéias que seria, ao mesmo tempo, uma análise dos erros que se poderia depois avaliar; ou uma decifração dos

1 Professor Doutor da Universidade Paulista (Unip) e pós-doutorando no Departamento de História da Universidade Estadual de Campinas (Unicamp). Artigo recebido em mar/07 e aprovado em mai/07. 
equívocos aos quais elas estão ligadas e dos quais poderia depender o que nós pensamos hoje. Se por pensamento se entender o ato que põe, em suas diversas relações possíveis, um sujeito e um objeto, uma história crítica do pensamento seria uma análise das condições nas quais se formaram ou se modificaram certas relações de sujeito a objeto, na medida em que estas são constitutivas de um saber possível. (Huisman, 1984, I, p.944)

Na verdade, sob o pseudônimo de Maurice Florence, é o próprio Foucault que escreve esta breve autobiografia (as iniciais M. F. permitiam identificar Foucault por trás de Maurice Florence). Neste texto, Foucault reivindica o legado da filosofia crítica e do kantismo e especifica sua própria prática da filosofia crítica. ${ }^{2}$

A "História crítica do pensamento", reivindicada por Foucault, distingue-se da história das idéias tradicional por procurar as condições de possibilidade do pensamento a partir da análise da constituição recíproca do sujeito e do objeto e, deste modo, se reconhece como uma filosofia crítica ainda tributária do kantismo. Mas cabe interrogar qual é o estatuto deste kantismo.

Outros filósofos contemporâneos, como Jürgen Habermas e John Rawls, também reivindicam a herança kantiana, mas numa perspectiva muito distinta de Foucault, defendendo a necessidade de valores e normas universais, encarnados na esfera pública e nas instituições do Estado de direito. Foucault, porém, rejeita a idéia de valores ou normais universal, além de ter feito uma crítica radical do "monstro frio", o estado moderno, em seus cursos sobre a biopolítica e a razão de Estado. ${ }^{3}$ Assim, é preciso antes determinar que leitura Foucault faz de Kant, para entender qual o sentido desta filiação reivindicada.

Tendo em vista o momento em que foi escrito o verbete para o Dictionnaire des Philosophes, parece claro que Foucault quer com esse gesto, de alguma forma reafirmar o projeto moderno reivindicando também para si a herança kantiana, que é o primeiro projeto desta modernidade, contra um certo pós-modernismo para o qual a modernidade seria uma narrativa terminada. Mas qual interpretação Foucault faz da modernidade e do kantismo? Em que essa interpretação contribui para esclarecer o itinerário de seu pensamento? São questões que só podem ser respondidas após um exame cuidadoso da crítica que Foucault faz da modernidade, e o ponto de partida

2 O texto foi retomado nos Dits et Écrits (Foucault, 1994, IV, 631-636).

3 Nos cursos Défendre la Société; Sécurité, Territoire, Population e Naissance de la Biopolitique, ministrados no Collège de France na década de 1970, Foucault realizou a crítica genealógica do Estado moderno, deslocando o eixo de suas pesquisas da micropolítica e do poder disciplinar para as técnicas globais de governamentalização da sociedade. 
para este questionamento é o vínculo que Foucault estabeleceu com Kant, desde o início de sua obra até seus últimos textos. Nesse sentido, é significativo que Foucault tenha começado sua obra fazendo uma interpretação da Antropologia de um ponto de vista pragmático de Kant, e a tenha terminado, ou interrompido, por uma leitura renovada da filosofia crítica a partir de uma reflexão sobre o texto "Was ist Aufklãrung?" de Kant. O "enigma kantiano", como Foucault o chama numa de suas entrevistas, percorre seu pensamento de ponta a ponta, como um fio condutor subterrâneo e pode ser considerado uma das suas vias de entrada.

Evidentemente, não é possível tratar da recepção de Kant no pensamento de Foucault no âmbito de um artigo. Esta seria uma tarefa de fôlego, assunto para toda uma tese. O que pretendemos aqui é apenas dar algumas indicações sobre a relação que Foucault estabelece não somente com a obra de Kant, mas com o próprio projeto da modernidade. Abordaremos, inicialmente, a leitura que Foucault faz de Kant na época em que publicou $A_{S}$ Palavras e as Coisas, observando uma tensão que se estabelece entre o projeto crítico e o antropologismo kantiano e em seguida interrogaremos sua relação com Kant a partir de alguns de seus últimos textos, nos quais Foucault procura uma "ontologia do presente".

\section{Kantismo sem sujeito transcendental}

Comecemos com uma resenha que Foucault fez do livro de Cassirer, A filosofia do esclarecimento, ${ }^{4}$ que na ocasião tinha sido traduzido pela primeira vez para o francês. Essa resenha foi publicada no mesmo ano em que As Palavras e as Coisas, 1966, relacionando-se com a problemática desta obra, onde Kant é uma referência central. Foucault começa analisando o neokantismo de Cassirer:

Cassirer é neokantiano. O que se designa por esse termo é, mais que um movimento ou uma escola filosófica, a impossibilidade em que se encontrou o pensamento ocidental de superar o corte estabelecido por Kant: o neokantismo (neste sentido, todos nós somos neokantianos), é a injunção sempre renovada de reviver este corte - ao mesmo tempo para reencontrar sua necessidade e para tirar-lhe toda a medida. (Foucault, 1994, II, 546)

O corte estabelecido por Kant instaurou a modernidade como a "época da crítica" permanente, à qual tudo, sem exceção, tem que se submeter. No primeiro prefácio à Crítica da Razão Pura, Kant diz:

4 O título original é Die Philosophie der Aufklärung, publicado em 1932, a tradução francesa, La philosophie des Lumières, foi publicada pela editora Fayard em 1966. 
A nossa época é a época da crítica, à qual tudo tem que se submeter. A religião, por sua santidade, e a legislação, por sua majestade, querem igualmente subtrair-se a ela. Mas então suscitam contra elas justificadamente suspeitas e não podem aspirar ao sincero respeito, que a razão só concede a quem pode sustentar o seu livre e público exame. (Kant, 1997, p.5)

Segundo Foucault, a filosofia crítica de Kant instituiu o corte epistemológico que funda a modernidade. Esse corte kantiano coincide com o que Foucault chama, nas Palavras e as coisas, de "acontecimento" - entendido positivamente como fato discursivo, o acontecimento que deu origem à modernidade localiza-se precisamente na curva entre os séculos XVIII e XIX, quando emerge uma nova configuração epistemológica.

Foucault também atribui a Cassirer a invenção de um método, ao mesmo tempo transcendental e histórico, para abordar a história das idéias, método que ele vê como precursor da sua arqueologia. Este novo método opõe-se à história das idéias tradicional, pois não busca a gênese das idéias na psicologia dos sujeitos, não pressupõe um núcleo interno de sentido e interdita procurar a causa das idéias nas condições sociais e econômicas que lhes são exteriores. A emergência das idéias é explicada através da autonomização do seu campo teórico de emergência, ou seja, na busca pelas suas condições de possibilidade:

Cassirer procede segundo uma espécie de abstração fundadora: de um lado, ele apaga as motivações individuais, os acidentes biográficos e todas as figuras contingentes que povoam uma época: de outro lado, ele afasta ou ao menos deixa em suspenso as determinações econômicas ou sociais. [...] Ele isola de todas as outras histórias (a dos indivíduos, assim como a das sociedades) o espaço autônomo do teórico: e sob seus olhos se revela uma história até então muda. (Foucault, 1994, I, p.547-548)

A descoberta de "uma história até então muda" também é o objetivo da arqueologia do saber, método de investigação empregado nos primeiros livros de Foucault. ${ }^{5}$ As duas principais exigências metodológicas da arqueologia são: 1) purificar o campo discursivo dos elementos psicológicos, da intencionalidade dos sujeitos - considerados meros efeitos de superfície - e 2) autonomizar o discurso, separando-o e isolando-o do seu contexto sócioeconômico e deixando de considerá-lo como mero reflexo das infra-estruturas, como na teoria marxista da história. A possibilidade de "deixar entre parênteses" as determinações subjetivas e sócio-econômicas, isolando do

5 Como diz Canguilhem: "[...] o termo arqueologia diz bem o que ele quer dizer. É a condição de uma outra história, na qual o conceito de acontecimento é conservado, mas onde os acontecimentos afetam conceitos e não homens" (Ganguilhem, 1967, p.607). 
processo histórico como um todo a dimensão da linguagem pura, envolve um pressuposto teórico fundamental - o de que o processo histórico não é unitário, mas constituído de uma pluralidade de temporalidades irredutíveis umas às outras. Isolar a dimensão do discurso puro seria uma operação semelhante à redução química dos elementos de uma mistura complexa, isolando somente um dos elementos para obtê-lo em estado puro. Esta operação aplicada à história das idéias, se bem sucedida, demonstraria que não há uma temporalidade única, nem um núcleo único de sentido a partir do qual as diferentes temporalidades pudessem ser hierarquizadas, haveria apenas uma absoluta dispersão temporal, sem centro nem totalidade - uma temporalidade atonal e aberta.

Esta operação arqueológica foi experimentada nas Palavras e as Coisas, que Foucault considerava um "livro de trabalho", radicalizando o método até então empregado na História da Loucura e no Nascimento da Clínica - onde ainda se pressupunha um centro de sentido na forma de uma estrutura unitária (a divisão "trágica" entre razão e desrazão no caso da História da loucura e a unidade do "olhar médico" no caso do Nascimento da clínica). Isso explica porque, nas Palavras e as Coisas, são deixadas entre parênteses as dimensões concretas do sujeito e da sociedade: não se trataria de reduzir tudo à linguagem, mas de cindir o tempo, marcando uma temporalidade interna ao próprio discurso, independente das determinações extradiscursivas.

Contudo, esse procedimento de autonomização do teórico configura um kantismo às avessas, ao qual se poderia aplicar a mesma expressão que Paul Ricoeur utilizou para caracterizar a antropologia de Lévi-Strauss: é um "kantismo sem sujeito transcendental". Ao autonomizar o campo discursivo da referência ao sujeito constituinte, Foucault abandona a necessidade de um princípio transcendental, de forma que a arqueologia dispensa a necessidade de um ponto fixo ou de uma referência absoluta em valores universais para pensar a historicidade dos discursos. Assim, poderíamos questionar a vocação "neokantiana" reivindicada por Foucault, pensando na batalha permanente que Foucault travou contra todas as expressões da filosofia do sujeito.

\section{O "sono antropológico" da filosofia crítica}

Segundo Foucault, Kant fundou a antropologia como "analítica da finitude" quando encontrou os limites do cogito cartesiano na finitude humana (que é tanto a finitude da consciência, que não pode saber tudo, quanto os próprios limites físicos do corpo humano), reportando a possibilidade do conhecimento precisamente a esse limite. Antes do momento kantiano, a filo- 
sofia colocava a questão do homem a partir do pensamento do infinito e da verdade como valor absoluto. Não havia um questionamento sobre os limites do próprio conhecimento porque o conhecimento era considerado um dado prévio ao ato de conhecer. Nas metafísicas clássicas, o problema do conhecimento se colocava em termos de erros e ilusões e a questão fundamental se colocava da seguinte maneira: como posso saber se meu conhecimento é real ou se estou sendo enganado pelos meus sentidos, pela minha consciência ou mesmo por um gênio maligno?

A partir do momento em que o conhecimento é problematizado a partir das faculdades humanas - sensibilidade, entendimento e razão - coloca-se naturalmente a questão dos limites do conhecimento e, por conseguinte, o conhecimento racional da realidade em si torna-se impossível. Segundo Foucault, portanto, foi ao fundamentar a possibilidade do conhecimento na finitude humana, que Kant rompeu com a tradição metafísica e inaugurou o pensamento moderno. Mas, ao mesmo tempo, Kant mergulhou a filosofia crítica num novo "sono dogmático", substituindo o conhecimento absoluto da metafísica clássica pelo sujeito transcendental como novo absoluto. Como diz Foucault, este é "o enigma kantiano que, após cerca de duzentos anos, enfeitiçou o pensamento ocidental, tornando-o cego a sua própria modernidade" (Foucault, 1994, I, p.547).

Foucault quer apreender o significado total do corte kantiano, em toda a sua radicalidade, mas quer, ao mesmo tempo, apreender o impensado da crítica kantiana, o seu momento dogmático, que entorpeceu o pensamento moderno aprisionando-o na circularidade da analítica da finitude. Para esclarecer essa questão, voltemos um pouco atrás na cronologia da obra de Foucault. Quando defendeu sua tese de doutorado Histoire de la folie à l'âge classique, em 1961, Foucault apresentou também uma tradução crítica da Antropologia de um ponto de vista pragmático de Kant, até então inédita em francês (Kant, 1964), precedida de uma longa introdução onde eram criticadas as analíticas da finitude. A tradução de Foucault foi publicada em 1964, estranhamente sem essa introdução.

Essa Introdução é fundamental para entendermos o papel da crítica kantiana na formulação da arqueologia. Comentando a Introdução de Foucault, Ricardo Terra afirma (Terra, 1998, p.146): "A Introduction à l'antropologie de Kant é o esboço parcial de uma obra que visaria criticar as antropologias filosóficas contemporâneas". Utilizando um método simultaneamente estrutural e genético, Foucault analisou as diversas versões da antropologia de Kant, associando-as à elaboração das três críticas kantianas e defendeu que as três grandes questões críticas "O que posso saber?", "O que devo fazer?" e "O que me é lícito esperar?" estão relacionadas a uma quarta, "O que é o homem?" (Terra, 1998, p.151-156). Se, como sabemos, as três questões críticas se traduzem respectivamente como a procura do limite da ra- 
zão, da extensão do entendimento e das fontes da sensibilidade, Foucault conclui que a quarta questão, "O que é o homem?", é o seu complemento necessário. Porém, desta maneira a filosofia crítica é encarcerada no círculo formado pela analítica da finitude, pois o fundamento último da crítica é ele próprio empírico e, portanto, não crítico. Assim, para Foucault, constitui-se no interior do pensamento kantiano uma tensão não resolvida, entre crítica e antropologia, tensão entre a necessidade de criticar todo conteúdo de conhecimento, remetendo-o à universalidade do sujeito transcendental e a necessidade oposta de fundamentar a crítica numa antropologia empírica, ou seja, no que é o homem em sua essência. Segundo Foucault, que discute aqui o problema do fundamento recíproco da liberdade e da natureza em Kant:

[...] a Antropologia é conhecimento do homem, em um movimento que o objetiva, no nível de seu ser natural e no conteúdo de suas determinações animais: mas ela é conhecimento do conhecimento do homem, num movimento que interroga o sujeito sobre ele mesmo, sobre seus limites, e sobre aquilo que ele autoriza no saber que dele se tem. (apud Terra, 1998, p.157)

Já está aqui delineado o "círculo antropológico" no qual incide a analítica da finitude ao tentar fundamentar todo conhecimento na finitude do sujeito humano, confundindo o empírico e o transcendental, questão que Foucault desenvolve no capítulo "O homem e seus duplos", na segunda parte das Palavras e as coisas (Foucault, 1966, p.314-354). A partir desta interpretação do pensamento kantiano, Foucault enceta sua crítica às antropologias filosóficas, ou seja, a todas as filosofias que pretendem dizer o que é o homem em sua essência. O contra-senso básico é querer que a antropologia absorva as prerrogativas da crítica, com a pretensão de fundar as ciências humanas partindo de um campo empírico. Perde-se assim a dimensão crítica do limite, fazendo valer como transcendental aquilo que, na verdade, é empírico. Podemos ver como a tese sobre Kant forneceu a argumentação para a crítica foucaultiana das filosofias do sujeito, entendidas como um novo "sono dogmático" que enfeitiçou o pensamento moderno.

\section{Crítica e "ontologia do presente"}

Dando um salto na cronologia, notemos que mais de vinte anos depois da Introdução à Antropologia de Kant, Foucault retoma a questão da filosofia crítica kantiana, para desta vez lhe dar um conteúdo mais positivo. Ressaltando a ligação estreita entre Kant e a modernidade, Foucault ressalta a permanência desde Kant da obrigação da crítica, da crítica como atitude: 
[...] se a filosofia moderna, tanto a do século XIX, como a do século XX, deriva em grande parte da questão kantiana "Was ist Aufklärung?", isto é, se admitimos que a filosofia moderna teve entre suas funções principais, a função de se interrogar sobre o que foi este momento histórico no qual a razão pode aparecer sob sua forma "maior" e "sem tutela", a função da filosofia do século XIX consiste, então, em perguntarmos o que é este momento no qual a razão acede à autonomia, o que significa a história da razão e qual valor devemos conceder à dominação da razão no mundo moderno através das três grandes formas do pensamento científico, da aparelhagem técnica e da organização política. (Foucault, 1994, IV, p.438)

Em seu comentário sobre o texto "Was ist Aufklärung?", um dos opúsculos de Kant sobre a filosofia da história, Foucault esclarece o que entende por modernidade (1994, IV, p.562): "Ao me referir ao texto de Kant, eu me pergunto se não poderíamos considerar a modernidade mais como uma atitude do que como um período da história [...] Um pouco, sem dúvida, como o que os Gregos chamam de um ethos". Definindo o que entende por modernidade e colocando-se a si próprio como herdeiro desta modernidade e, portanto, do projeto do esclarecimento, Foucault delimita o âmbito de seu próprio pensamento, rejeitando o rótulo de pós-moderno, com o qual Habermas o alcunhara (Habermas, 1990, p.225-249). Foucault reitera seu ponto de vista próprio, afirmando que (Foucault, 1994, IV, p.571): "[...] o fio que pode nos ligar desta maneira à Aufklärung não é a fidelidade a elementos de doutrina, mas a reativação permanente de uma atitude, isto é, de um ethos filosófico que se poderia caracterizar como crítica permanente de nosso ser histórico".

O corte epistemológico instituído com a crítica kantiana, de acordo com o ponto de vista de Foucault, não pode ser efetivamente superado porque a modernidade não é pensada como uma época, cujo fim poderia ser decretado, mas como uma atitude que, enquanto tal, não tem época. A filosofia crítica tem na obrigação ética de reatualizar permanentemente a crítica como atitude, instituindo novas rupturas, seu correlato prático necessário.

Além disso, reconhecendo a filiação kantiana de seu projeto filosófico, Foucault pode dar legitimidade à pesquisa arqueológico-genealógica, pensada como uma crítica imanente da racionalidade no seu processo histórico de formação e transformação. Como tentamos demonstrar aqui, este fundamento kantiano da obra de Foucault está presente em toda a sua obra, desde a Introdução à Antropologia de Kant até o último curso sobre a parresía na Grécia Antiga (Foucault, 2004) e funciona como um fio condutor subterrâneo para compreender o itinerário de seu pensamento.

Para Foucault, Kant está vinculado à modernidade porque foi o primeiro filósofo a analisar filosoficamente um acontecimento histórico, a por o presente em questão, quando se perguntou em seu famoso texto de 1784: "Quem somos nós? Quem somos nós enquanto Aufklärer, enquanto testemunhos desse século das Luzes? Comparemos com a questão cartesiana: 
quem sou eu? Eu, enquanto sujeito único, mas universal e não histórico?" (Foucault, 1994, IV, 231). "Qual é este acontecimento que chamamos Aufklärung e que determinou, ao menos em parte, o que nós somos, o que nós pensamos e o que nós fazemos hoje?" (Foucault, 1994, IV, 562). O tipo de interrogação filosófica inaugurado pela pergunta de Kant "Was ist Aufklärung?" problematiza a relação entre a historicidade do sujeito, o presente vivido, e a constituição de si mesmo como sujeito autônomo, como sujeito de seu próprio esclarecimento.

O que está em questão para a crítica genealógica, portanto, é sempre o presente. Nesse sentido, Foucault se opõe a uma certa maneira de pensar o tempo, que vê o presente como um momento crítico de uma decisão soberana, momento no qual tudo declina e tudo recomeça. É ainda assim que Lyotard, por exemplo, pensa o advento da pós-modernidade, como momento final da desvalorização de todos os valores, do colapso das "metanarrativas" universais que legitimavam o "nós" moderno. ${ }^{6}$

Esse não é o caminho de Foucault. Contra a idéia pós-moderna do "desmoronamento da razão" e do fim das narrativas legitimadoras, Foucault afirma que outras formas de racionalidade se criam sem parar: a Razão está em perpétua transformação. Para Foucault, essa forma de pensar traduz o que ele considera um dos "hábitos mais nocivos do pensamento contemporâneo":

A análise do momento presente como sendo precisamente na história aquele da ruptura, ou aquele da culminância [sommet], ou o da consumação [accomplissement], ou o da aurora que retorna. A solenidade com a qual toda pessoa que produz um discurso filosófico reflete seu próprio momento me parece um estigma. Digo isso justamente por já ter acontecido comigo; digo além do mais que, em alguém como Nietzsche, isso se encontra sem parar, ou ao menos de maneira por demais insistente. Creio que é preciso ter a modéstia de dizer que, por um lado, o momento em que vivemos não é esse momento único, fundamental ou irruptivo da história a partir do

6 Lyotard parte da filosofia negativa da história de Adorno, para afirmar que a modernidade é um projeto terminado, com o súbito colapso do seu horizonte de sentido e de todos os discursos universais que a legitimavam: "O pensamento e a ação dos séculos XIX e XX são regidos por uma Idéia (entendo Idéia no sentido kantiano). Esta Idéia é a da emancipação. A sua argumentação é, de fato, diferente conforme aquilo a que se chamam as grandes filosofias da História, as grandes narrativas nas quais se tenta ordenar a enorme quantidade de acontecimentos: narrativa cristã da redenção do pecado adâmico pelo amor, narrativa aufklärer da emancipação da ignorância e da servidão pelo conhecimento e o igualitarismo, narrativa especulativa da realização da Idéia universal pela dialética do concreto, narrativa marxista da emancipação da exploração e da alienação pela socialização do trabalho, narrativa capitalista da emancipação da pobreza pelo desenvolvimento tecnoindustrial. Há entre estas narrativas matéria para litígio e mesmo para diferendo. Mas todos situam os dados que os acontecimentos trazem no curso de uma história cujo termo, mesmo permanecendo inatingível, se chama liberdade universal, absolvição da humanidade inteira" (Lyotard, 1987, p.38-39). 
qual tudo termina e tudo recomeça; é preciso ter a modéstia de dizer, ao mesmo tempo, que - mesmo sem esta solenidade - o momento em que vivemos é muito interessante, e precisa ser analisado, decomposto e que, com isso, temos que nos colocar a questão: o que é o hoje?. (Foucault, 1994, IV, 692)

\section{Entre o "tribunal da razão" e a "vontade de verdade": a noção de limite}

Não obstante essa interpretação original da relação entre crítica da razão e Aufklärung, o "kantismo" de Foucault não é de forma nenhuma ortodoxo e o próprio estatuto da crítica em Foucault permanece problemático, principalmente por não haver mais a separação kantiana entre as faculdades, constituindo uma crítica que é ao mesmo tempo empírica e transcendental, pois os conteúdos históricos valem para ela como condição de possibilidade. É uma crítica onde a noção de limite não se confunde com a negação ou com a contradição, o que a incompatibiliza com as abordagens ligadas à dialética hegeliana. Teremos então que refletir agora sobre a divergência sobre a noção de limite em Kant e em Foucault.

Desde a História da Loucura, publicada em 1961, desponta na obra de Foucault a intenção de fazer uma crítica imanente da racionalidade ocidental a partir das distintas figuras que simbolizam os "outros" da razão. Desta forma, loucura, doença, morte, crime e sexualidade afiguram-se como "experiências limites" a partir das quais a razão ocidental constituiu negativamente sua identidade. No primeiro prefácio à História da Loucura, Foucault afirma que pretende realizar uma história da razão pelo avesso, "fazer uma história dos limites com os quais uma cultura rejeita algo que será para ela o exterior" (Foucault, 1972, p.9) e, numa entrevista desse mesmo período, esse projeto é assim descrito:

Pareceu-me interessante tentar compreender nossa sociedade e nossa civilização através de seus sistemas de exclusão, de rejeição, de recusa, através daquilo que ela não quer, seus limites, a obrigação na qual ela se encontra de suprimir um certo número de coisas, de pessoas, de processos, o que ela deve deixar cair no esquecimento, seus sistemas de repressão-supressão. (Foucault, 1994, II, p.158; grifo nosso)

A pesquisa arqueo-genealógica é concebida, então, como uma história subterrânea da racionalidade, um inventário documentado dos seus "limites", cuja função seria pôr a descoberto as origens históricas da racionalidade aplicada ao homem enquanto objeto de saber e alvo de técnicas políticas de dominação. Porém, esta crítica não se realiza mais a partir da figura kantiana do "tribunal da razão", responsável por delimitar as fronteiras e estabelecer o critério que separa o uso legítimo do uso ilegítimo da razão. Mas 
a crítica da razão, genealogicamente reformulada, abre mão de qualquer perspectiva transcendental ou intenção normativa, recusando-se a submeter o material histórico à lógica abstrata do conceito. Na perspectiva genealógica, é somente a partir da pesquisa histórica - documental e empírica que a crítica imanente da racionalidade poderá se realizar, evitando o risco de cair na abstração.

Para entender a distinção entre a crítica foucaultiana da "vontade de verdade" e o "tribunal da razão" kantiano, teremos que nos reportar agora ao prefácio à primeira edição da Crítica da Razão Pura de Kant, onde curiosamente comparece a metáfora da "genealogia", mas num sentido muito distinto do que a expressão, promovida a método de investigação, adquirirá a partir de Nietzsche.

No prefácio à edição de 1781 da Crítica da Razão Pura, Kant utiliza a metáfora da genealogia para criticar a pretensão da "rainha" metafísica de ser uma ciência, mostrando que ela não deriva das mais altas faculdades humanas, mas do senso comum e do preconceito (Kant, 1997, A X):

Embora essa suposta rainha tivesse um nascimento vulgar, derivasse da experiência comum e, por isso, com justiça, a sua origem tornasse suspeitas as suas exigências, aconteceu, no entanto, que esta genealogia tinha sido imaginada falsamente e, assim, a metafísica continuou a afirmar as suas pretensões [...].

Kant contesta os foros de nobreza que a metafísica se atribui para legitimar sua pretensão à verdade e à universalidade, negando-lhe o estatuto de ciência.

Noutro trecho do mesmo prefácio, surge a figura do "tribunal da razão", responsável por estabelecer o uso legítimo ou ilegítimo do conhecimento. A tarefa da razão, diz Kant, é a do conhecimento de si mesma e da constituição de um tribunal que lhe assegure as pretensões legítimas e, em contrapartida, possa condenar-lhe todas as presunções infundadas; e tudo isto, não por decisão arbitrária, mas em nome das suas leis eternas e imutáveis. Esse tribunal outra coisa não é que a própria Crítica da Razão Pura. (Kant, 1997, A XII)

Como vemos, Kant troca um absoluto por outro, substituindo o absoluto da metafísica pelo absoluto da ciência, mas não critica a própria ciência como ideal, a "vontade de verdade" que se encontra por trás do ideal científico permanece inquestionada. Para suspender a legitimidade da própria ciência, entendida como "vontade de verdade", seria preciso abrir mão do princípio transcendental e invalidar a possibilidade mesma da constituição de um "tribunal da razão". É preciso, então, esclarecer a especificidade da crítica kantiana da metafísica para depois confrontá-la com a crítica genealógica, que ao mesmo tempo herda e suplanta a crítica kantiana da razão.

Kant criticou tanto a tradição racionalista, quanto a tradição empirista, por acreditarem na existência de uma realidade em si mesma (a coisa-em-si) e fazer afirmações sem fundamento sobre a essência da realidade. Segundo 
Kant, toda afirmação sobre a realidade em si mesma, sobre a sua essência, é uma afirmação metafísica e, portanto, é um uso ilegítimo da razão, pois ultrapassa o limite da experiência possível. Em vez de perguntar se o conhecimento deriva dos sentidos ou da razão, a filosofia transcendental deve se questionar sobre as condições de possibilidade do próprio conhecimento.

Fundando a filosofia transcendental, Kant quis determinar as condições formais que tornam possível o conhecimento e a experiência, tendo encontrado essas condições no sujeito universal. A filosofia transcendental não seria, então, conhecimento de objetos, mas conhecimento sobre o modo como o objeto é construído por um sujeito para um conhecimento possível, investigação sobre a natureza do próprio ato de conhecer. Para Kant, não se deve partir do objeto a conhecer, mas do sujeito que conhece, pois os objetos do pensamento não estão na própria realidade, mas no intelecto legislador que prescreve suas leis à realidade. Porém, esse sujeito não se confunde com a consciência individual, ele remete à unidade da razão humana, que se mantém una face à multiplicidade dos objetos do conhecimento. Com a filosofia transcendental de Kant, a função da filosofia deixa de ser a de especular sobre o supra-sensível e passa a ser a de esclarecer a natureza do próprio entendimento humano. Desta forma, Kant pensava promover a metafísica ao estatuto de uma verdadeira ciência, conferindo a ela, através da doutrina das faculdades, os foros de nobreza que lhe faltavam.

Para Foucault, a tarefa específica da filosofia crítica seria a reflexão sobre os limites, mas a noção foucaultiana de limite rompe com a perspectiva transcendental e normativa de Kant. Em Kant, os limites são entendidos como a fronteira intransponível do conhecimento (a da experiência possível), que não poderia ser ultrapassada sob risco de ir além das prerrogativas legítimas da razão humana. Contrariamente, Foucault pensa o limite como a transgressão necessária, como destruição de falsas evidências e rompimento radical com hábitos instituídos de pensamento. Daí a divergência de Foucault com Kant quanto ao sentido da noção de limite:

A crítica é a análise dos limites e a reflexão sobre eles. Mas, se a questão kantiana era de saber a quais limites o conhecimento deve renunciar a ultrapassar, me parece que a questão crítica hoje deve ser revertida em questão positiva: no que nos é dado como universal, necessário, obrigatório, qual é a parte do que é singular, contingente e devida a obstáculos arbitrários. Trata-se, em suma, de transformar a crítica exercida na forma da limitação necessária numa crítica prática na forma do ultrapassamento [franchissement] possível. (Foucault, 1994, IV, p.574)

A noção de limite, portanto, é vista por Foucault de forma oposta à da filosofia transcendental de Kant. Foucault põe de cabeça para baixo a crítica kantiana ao renunciar ao sujeito transcendental, substituindo as condições formais de possibilidade da experiência por condições históricas (e, portan- 
to, sempre variáveis e contingentes) de possibilidade. Foucault acrescenta que, na sua concepção, a crítica "[...] não busca tornar possível a metafísica enfim tornada ciência; ela busca relançar tão longe e tão largamente quanto possível o trabalho indefinido da liberdade" (Foucault, 1994, IV, p.574).

\section{A genealogia como realização da crítica}

Gilles Deleuze foi um dos primeiros a reconhecer e dar importância ao kantismo de Foucault, analisando sua arqueologia a partir de dois princípios transcendentais - as visibilidades e os enunciados, o visível e o dizível. Porém, de acordo com Deleuze, Foucault de algum modo historiciza o transcendental, à procura das condições históricas e reais da experiência e não somente de condições formais e abstratas:

Não é uma história das mentalidades, nem dos comportamentos. Falar e ver, ou melhor, os enunciados e as visibilidades, são elementos puros, condições a priori sob as quais todas as idéias se formulam num momento e os comportamentos se manifestam. Essa busca das condições constitui uma espécie de neo-kantismo característico de Foucault. Há, entretanto, diferenças essenciais em relação a Kant: as condições são as da experiência real, e não as de toda experiência possível [...]; elas estão do lado do "objeto", do lado da formação histórica, e não de um sujeito universal (o próprio a priori é histórico); ambas são formas de exterioridade. (Deleuze, 1990, p.69)

Segundo Deleuze, Kant criticou as pretensões infundadas à verdade, mas não a própria idéia de verdade, questionou as pretensões infundadas à constituição da moral e da religião como valores absolutos, mas não a própria moral e a própria religião em si mesmas. A crítica kantiana seria um projeto inconcluso, pois ela acaba por legitimar a autoridade da ciência, do Estado e da religião sob os auspícios da razão prática. Mesmo se Kant lhes interdita as justificativas transcendentes e o privilégio do absoluto, a obediência aos valores estabelecidos continua sendo legitimada, mas agora a título de norma da razão prática. Segundo Deleuze, Kant teria se contentado em "inventariar valores existentes" e, assim, teria subtraído os valores à crítica. A verdadeira herdeira da crítica kantiana da razão seria a genealogia dos valores de Nietzsche, que ao introduzir os conceitos de sentido e valor na filosofia teria retomado o projeto crítico kantiano sobre novas bases e com novos conceitos. ${ }^{7}$

7 "Nietzsche nunca escondeu que a filosofia do sentido e dos valores deveria ser uma crítica. Kant não realizou a verdadeira crítica porque não soube colocar seu problema em termos de valores; este é então um dos principais móveis da obra de Nietzsche. [...] a filosofia dos valores, tal como ele a instaura e a concebe, é a verdadeira realização da crítica, a única maneira de realizar a crítica total, isto é, de fazer a filosofia 'a marteladas'" (Deleuze, 1962, p.1). 
A interpretação de Deleuze coincide com a de Foucault neste ponto, pois também para Foucault, Nietzsche teria sido aquele que realizou a verdadeira crítica imanente da razão. A genealogia nietzscheana seria o acabamento e a conseqüência lógica da crítica kantiana da razão. Parafraseando o que diz Marx sobre Hegel, poderíamos dizer que a crítica estava de cabeça para baixo, era ainda idealista, por isso era preciso recolocá-la sobre seus pés, fazê-la operar ao revés. Ao se tornar histórica e empírica, a crítica é obrigada a abrir mão do ponto fixo transcendental, ou seja, das condições abstratas, universais e formais (isso é, vazias) que tornam possível o conhecimento e a experiência, o que aproxima a crítica genealógica de um historicismo radical.

A crítica deixa de ser idealista para orientar-se para a materialidade da história, "[...] ela é genealógica na sua finalidade e arqueológica no seu método" (Foucault, 1994, IV, p.574). A crítica é arqueológica em seu método por tentar ser uma descrição pura de "acontecimentos discursivos", uma "análise diferencial de discursos-objetos" (Foucault, 1969, p.182), a partir da exterioridade, mantendo todo sentido e valor em suspenso, "entre parênteses", como uma redução fenomenológica. Ela é genealógica em sua finalidade por ser uma forma de desmistificar as pretensões da razão, denunciando o que está por trás dos valores fundamentais da cultura ocidental (razão, sujeito, autoridade, justiça), seguindo o modelo da Genealogia da Moral de Nietzsche.

Do ponto de vista tanto de Deleuze, quanto de Foucault, portanto, a genealogia nietzscheana seria a conclusão lógica, o acabamento da crítica kantiana. Ao invés de submeter a análise de toda a experiência possível ao sujeito transcendental como ponto fixo não histórico, a genealogia suprime o privilégio do sujeito, a perspectiva transcendental, e passa a buscar as condições de possibilidade da experiência e do conhecimento na contingência da história. Ou seja, a genealogia não se contenta com as condições ideais ou formais de possibilidade do conhecimento, ela busca suas condições materiais, contingentes e concretas, pois para ela sujeito e objeto são pólos do conhecimento que se constituem correlativamente, sem a referência a normas universais.

Foucault, portanto, faz a crítica caminhar do universalismo para o relativismo, do formalismo para o historicismo. Em vez de ser uma justificação transcendental dos valores estabelecidos, ela se torna demolição de ídolos, desmistificação de ideais, pondo em questão o próprio valor da verdade a partir dos "efeitos de poder" de que os discursos de verdade são inseparáveis. O objetivo de Foucault, portanto, é o de criticar as racionalizações políticas, desmontando suas pretensões através de uma complexa morfologia histórica das distintas formas da "vontade de verdade". É somente tornando-se capaz de questionar seus próprios efeitos de poder e de reconhecer a 
mutualidade entre saber e poder, que a crítica poderá se tornar imanente e reflexiva. É por essa razão que a crítica é redefinida por Foucault como uma atitude e não como proposição de valores universais e normas invariáveis.

A crítica, tal como formulada por Kant, tem a função de conduzir o homem ao estado de maioridade, libertando-o das ilusões transcendentais que o aprisionam. Podemos dizer que Foucault, sob o influxo da genealogia nietzscheana, submete o projeto crítico a uma metamorfose, que o desembaraça dos resíduos transcendentais e idealistas que ele ainda carregava em Kant, mas mantendo a perspectiva emancipatória. A crítica genealógica ao mesmo tempo herda e suplanta a crítica kantiana da razão. Ela permanece ligada umbilicalmente ao projeto de autonomia da Aufklärung, à superação do estado de minoridade e à libertação dos diferentes pretendentes a "tutores" da humanidade, mas simultaneamente propõe a autocrítica da modernidade e das conseqüências políticas do desenvolvimento da razão, da ciência e da técnica, que permaneciam impensadas na filosofia transcendental kantiana. A crítica genealógica relança o empreendimento kantiano, introduzindo novos conceitos e métodos de investigação, a fim de operacionalizá-lo para enfrentar os desafios de um presente em mutação.

Concluímos que o kantismo de Foucault constitui uma tentativa de síntese entre o formalismo das condições de possibilidade e um historicismo radical, de modo que a crítica torne-se desmistificação e transgressão permanente, em vez de apenas legitimar o que já existe. Poderíamos dizer que Foucault faz a crítica das políticas da verdade com Kant numa mão e Nietzsche na outra, procurando uma síntese (talvez impossível) entre os dois lados. O kantismo de Foucault é um "kantismo para além de Kant", que busca realizar uma avaliação de toda a herança da modernidade, centrada na figura da subjetividade fundadora e no discurso do "homem" como novo transcendental e centro de sentido. Trata-se de avaliar o custo da modernidade, as suas implicações como escolha civilizacional, mas ao mesmo tempo descortinar as suas potencialidades não desenvolvidas de emancipação.

ALVES, Alexandre. The Critique turned upside-down: about the significance of Kant in Foucault's thought. Trans/Form/Ação, (São Paulo), v.30(1), 2007, p.25-40.

- ABSTRACT: This paper intends to evaluate the relationship Foucault establishes regarding modernity, taking as guide-line his link with Kant's thought. We approach, at a first moment, the interpretation Foucault gives from Kant in the period he was writing The Order of Things, remarking the tension between the critical project and the Kantian antropologism and, in a second moment, we question his relationship to Kant through some of his last texts, where Foucault is looking for an "ontology of the present".

- KEYWORDS: Aufklärung; critique; modernity; archaeology; genealogy; kantianism. 


\section{Referências bibliográficas}

ALVES, Alexandre. Crítica e Genealogia: A recepção de Nietzsche na obra de Foucault, 2006. 286 f. Tese (Doutorado em História) - Faculdade de Filosofia, Letras e Ciências Humanas, Universidade de São Paulo, São Paulo, 2006.

CANGUILHEM, Georges. Mort de l'homme ou épuisement du Cogito?. Critique, n.24, p.596-612, 1967.

CASSIRER, Ernst. La philosophie des Lumières, Paris: Fayard, 1966.

. Kant, Vida y Doctrina, México: Fondo de Cultura Económica, 1948.

DELEUZE, Gilles. Foucault, São Paulo: Brasiliense, 1990.

FOUCAULT, Michel. Les mots et les choses, Paris: Gallimard, 1966.

. Archéologie du Savoir, Paris: Gallimard, 1969.

. Histoire de la folie a l'âge classique, Paris: Gallimard, 1972.

Critique et Aufklärung. Bulletin de la Société française de Philosophie, v. LXXXIV, p.23-45, 1990.

Dits et écrits, 4 vol., Paris: Gallimard, 1994.

Discurso y Verdad en la Antigua Grécia. Barcelona: Paidós, 2004.

HABERMAS, Jürgen. O discurso filosófico da modernidade, São Paulo: Martins Fontes, 2003.

HAN, Béatrice. L'ontologie manquée de Michel Foucault, entre l'historique et le transcendental, Grénoble: Jerôme Millon, 2000.

HUISMAN, Denis. Dictionnaire des Philosophes, 2 v., Paris: PUF, 1984.

KANT, Immanuel. Antropologie du point de vue pragmatique, Paris, Vrin, 1964.

. Resposta à pergunta: Que é "Esclarecimento"?, Textos Seletos, Petrópolis: Vozes, 1974, p.100-17.

Crítica da razão pura, Lisboa: Calouste Gulbenkian, 1997.

LYOTARD, Jean-François. O pós-moderno explicado às crianças, Lisboa: Dom Quixote, 1987.

TERRA, Ricardo Ribeiro. Foucault leitor de Kant: da antropologia à ontologia do presente. Passagens, ensaios sobre a filosofia de Kant (Tese de Livre-docência em filosofia), Faculdade de Filosofia, Letras e Ciências Humanas, Universidade de São Paulo, São Paulo, 1998, p.145-60. 